\title{
Evidence of early amorphous arsenic sulfide production and use in Edo period Japanese woodblock prints by Hokusai and Kunisada
}

\author{
Marc Vermeulen * ${ }^{*}$ and Marco Leona
}

\begin{abstract}
This study explores the evolution of the manufacturing process of artificial arsenic sulfide pigments in Edo-period Japan through the analysis of three impressions of the same print dated from the 1830s and attributed to Katsushika Hokusai (1760-1849), and one from 1852 and attributed to Utagawa Kunisada (1786-1865). Colorants in the yellow and green areas of the four prints were investigated by means of non-invasive and microanalytical techniques such as optical microscopy, fiber optic reflectance spectroscopy and Raman spectroscopy. While the pigments in the green and yellow areas are similar throughout the set of prints_-Prussian blue, indigo (for the Hokusai prints) and orpiment were identified_optical microscopy and Raman spectroscopy highlighted some variations in the orpiment used in the green areas of the prints. Two of the Hokusai prints present bright yellow particles of larger size and lamellar morphology, identified by Raman spectroscopy as natural orpiment. The third print presents an admixture of bright yellow natural orpiment particles with a smaller number of orange-yellow particles shown by Raman to be partially amorphous arsenic sulfide. Small bright yellow particles identified as fully amorphous arsenic sulfide pigments by Raman were found throughout the green areas of the Kunisada print. Although supported by Japanese historical sources, local production of artificial arsenic sulfide in the early nineteenth century was not previously documented. The simultaneous presence of both crystalline and amorphous domains in a single pigment particle in some of the Hokusai prints suggests that natural orpiment was used as primary source of arsenic for the production of a low grade artificial pigment. The pigment found in the Kunisada print, by contrast, was obtained from arsenic oxide (or arsenolite) and sulfur though a dry-process synthesis, as shown by the sulfur excess, signs of heat treatments and fully amorphous nature of the pigment. These findings set the earliest dates for both the ore sublimation process and the arsenolite dry process, and are of foremost importance to understand the evolution of the amorphous arsenic sulfide production in Edo-period Japan and its introduction in the palette of Japanese woodblock prints.
\end{abstract}

Keywords: Japanese woodblock prints, Hokusai, Kunisada, Arsenic sulfide pigments, Raman spectroscopy, Synthesis

\section{Introduction}

Understanding the production timeline of Japanese woodblock prints can be a difficult task due to the commercial nature of this particular art form. For popular designs, several thousands of impressions would have been produced and sold [1-3], over a period of several months, and reprinting or reissuing a popular print well past the date of first issue (or recreating it altogether)

*Correspondence: marc.vermeulen@metmuseum.org

Department of Scientific Research, The Metropolitan Museum of Art, New York, NY 10028, USA would not have been unusual. While wear in the keyblock can give important indications on the relative chronology of production of individual impressions of the same print, pigment use is a valuable source of information towards dating and authenticating artifacts [4-7]. This approach has previously been applied to Japanese woodblock prints, using pigments such as synthetic ultramarine blue or orpiment as well as organic colorants as dating markers [3, 8-10].

Despite the great interest given to Hokusai works, little is known on the materials that have been used in the prints series. The palette of woodblock prints increases 
in breadth over the Edo period (1615-1868) to eventually encompass a very limited palette: dayflower blue, indigo and Prussian blue (the latter only starting from the 1820s); orpiment, gamboge, Armur cork tree (berberine dye), turmeric and ochres for the yellows; organic colorants (safflower, lac, sappanwood), red ochres, red lead and vermilion for the reds; and mixtures of blue and yellow for green $[3,11]$. Recent studies focusing on prints from the 1650 s to the 1800 , a period of time during which relations and trade between Japan and other countries were severely limited, showed clear evolution trends in the use of colorants, both organic and inorganic, in Japanese woodblock prints $[11,12]$. Following this period, the 1830s represent a transitional time in Japan regarding the materials used in woodblock prints. A remarkable color shift occurred with the introduction of Prussian blue in the 1820s, giving rise to a "blue revolution" [13], of which some of the Thirty Six Views-the aizuri-e-are a good examples [13]. The synthetic pigment was introduced by the Chinese and/or the Dutch, the only foreign merchants allowed in Japan at the time and quickly adopted by Japanese artists, including Hokusai, Hiroshige, and Kunisada. This proves that despite Japan's strict ban on all imports and exports, the Japanese printing industry was quite receptive to experimentation with new materials. While the widespread adoption of Prussian blue is the most striking proof of the dynamic attitude of Edo woodblock printers, it is by no means the only one. We have recently reported on the introduction of ultramarine blue and amorphous arsenic sulfide pigments in the palette of Japanese woodblock printers [8]. To date, these pigments appear only in prints from the last decade of the Edo period and more consistently in Meiji prints [8, 10].

Arsenic sulfide pigments have a place of particular interest in the history of pigment preparation and synthesis, because of the attractive color and high price of orpiment, the natural arsenic sulfide. Synthetic processes designed to obtain high quality pigment from low grade ores evolved drastically over time in Europe, going from the simple sublimation of natural pigments, in the fourteenth/fifteenth centuries, to a wet-processed synthesis in the nineteenth century [14]. The history of arsenic sulfide pigments in Japan is not as well documented. A number of studies have focused on pre- 1800 prints or late-Edo/early-Meiji prints [8, 10, 11, 15], but nothing has been done so far on the very crucial period of experimentation going from about 1830 to the early 1850s. This study fills this gap and provides tantalizing material evidence as to the beginning of the synthetic arsenic sulfide industry in Japan.

The Japanese Art collection at the Metropolitan Museum of Art (The Met) counts over 4000 woodblock prints and includes all 46 views (36 original and ten additional views) from the "Thirty-Six Views of Mount Fuji" series by Hokusai. This print series, of which the iconic Under the Great Wave off Kanagawa comes from, is arguably one of the most well-known and successful set of Japanese woodblock prints ever produced. The series was so popular that ten additional views were commissioned and the various views re-issued well past their original issue. One of the main difference between the original and the additional views is the use of dark blue outlines in the former whereas black outlines are used in the latter. The Met owns several impressions of the same views (usually from 2 to 4), for a total of 121 prints. Such complete collection of prints offers a rare opportunity to improve the knowledge on the materials and techniques used by the publishers over the course of the production run of a successful series such as the "Thirty-Six Views of Mount Fuji".

We are not often allowed to sample from Japanese woodblock prints, therefore, non-invasive techniques such as fiber optic reflectance spectroscopy (FORS), excitation-emission matrix (EEM) fluorescence spectroscopy, X-ray fluorescence (XRF), infrared (IR) or Raman spectroscopy have often been preferred to study the materials used in prints $[11,12,15,16]$. Some of these techniques, namely FORS, XRF and Raman spectroscopy, were applied to the characterization of the color palette used in the selected prints. Special attention was given to the yellow pigments found in the various hues of the green areas of the prints. The study focuses specifically on a set of three prints by Hokusai, titled Mishima Pass in Kai Province (Kōshū Mishima goe, Fig. 1) and belonging to the "Thirty-Six Views of Mount Fuji" prints series as well as on a portrait of kabuki actor Ichikawa Ebizô V as Hamamatsu in the play Kezori Kuemon by Utagawa Kunisada (Fig. 2).

\section{Materials and methods 1. Woodblock prints}

Three Japanese woodblock prints from the Met extensive Hokusai prints collection were selected for an indepth study (Accession number JP18, JP2556 and JP2970, Fig. 1). All three prints belong to the "Thirty-Six Views of Mount Fuji" series and represent Mishima Pass in Kai Province (Kōshū Mishima goe). Two prints (JP2556Fig. 1a, b and JP2970-Fig. 1c, d) present the blue outlines characteristic for the aizuri-e prints from the early 1830s while the third print (JP18-Fig. 1e, f) has black outlines, characteristic for later $1830 \mathrm{~s}$ reprints. For ease of read, JP2556 will be referred as print A, JP2970 as print $B$ and JP18 as print C.

The fourth print (referred to as print $\mathrm{D}$ ) on which this study focuses is a portrait of kabuki actor Ichikawa Ebizô 

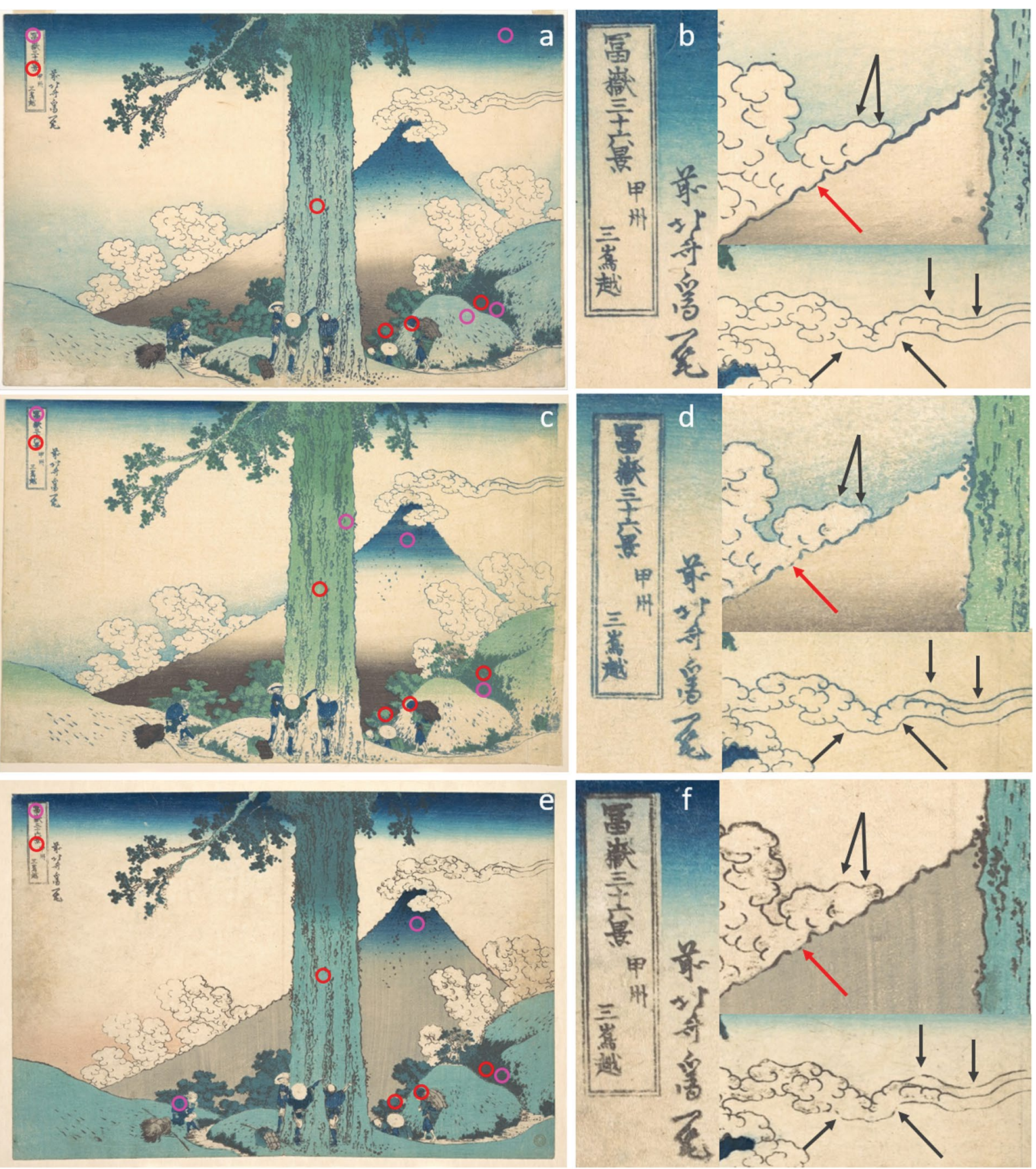

Fig. 1 a, c, e Images of three prints of Mishima Pass in Kai Province (Kōshū Mishima goe) and $\mathbf{b}$, $\mathbf{d}$, $\mathbf{f}$ respective details showing the variations in lines quality and keyblock wear, from the series Thirty-six Views of Mount Fuji (Fugaku sanjürokkei) by Katsushika Hokusai, ca. 1830-32, The Metropolitan Museum of Art. a, b Print A, Accession Number JP2556, $24.8 \times 37.5 \mathrm{~cm}$. The Howard Mansfield Collection, Purchase, Rogers Fund, 1936; c, d Print B, Accession Number JP2970, $24.4 \times 37.8$ cm. Henry L. Phillips Collection, Bequest of Henry L. Phillips, 1939 and e, f Print C, Accession Number JP18, $24.4 \times 36.5 \mathrm{~cm}$. Rogers Fund, 1914. In-situ Raman and FORS analyses are respectively indicated by red and pink circles

$\mathrm{V}$ as Hamamatsu in the play Kezori Kuemon by Utagawa Kunisada (Fig. 2). The print is titled Hamamatsu, Kezori Kuemon and is part of the series "The Fifty-Three Stations of the Tokaido". It is dated 2nd month of 1852 (March 13th-April 12th 1852 in the Gregorian calendar). The print is from the private collection of Henry D. Smith II. 


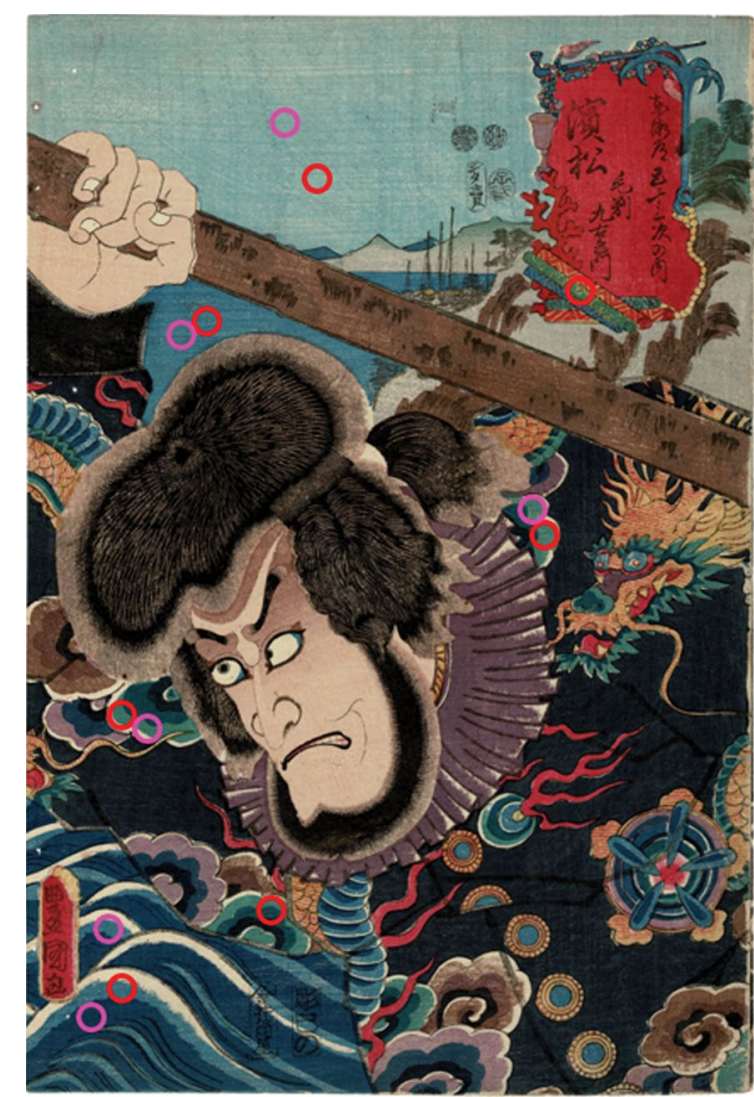

Fig. 2 Image of print D. Collection number 15.07 h. Hamamatsu, Kezori Kuemon from the series The Fifty-Three Stations of the Tokaido by Utagawa Kunisada, $35.2 \times 23.8 \mathrm{~cm}$, 2 nd month of 1852, Collection of Henry D. Smith II. In-situ Raman and FORS analyses are respectively indicated by red and pink circles

Due to the nature of the works, no samples were taken and only non-invasive Raman and fiber optic reflectance spectroscopy (FORS) analyses were carried out. The locations for the in-situ Raman (red circles) and FORS (pink circles) analyses are indicated in Figs. 1, 2.

\section{Fiber optic reflectance spectroscopy (FORS)}

Fiber optic reflectance spectroscopy was performed with an Ocean Optics QE65 Pro spectrometer (Dunedin, FL, USA) equipped with an Ocean Optics HL-2000 Tungsten halogen light source. The detector and light source were connected with a high $\mathrm{OH}$-fused silica fiber optic bundle consisting of eight $600 \mu \mathrm{m}$ fibers (used to transport the light from the source to the sample) arranged around a single $800 \mu \mathrm{m}$ fiber (to transport the signal from the sample to the detector). The distal end of the probe is partially fused to form a spherical lens that focuses both illumination and detection fibers to the same spot, with a working distance of approximately $1 \mathrm{~mm}$.
The spectral range of the detector is $200-1000 \mathrm{~nm}$; nevertheless, due to poor light output on the extremes of the range, only the range between 400 and $950 \mathrm{~nm}$ was considered. Spectra were referenced against the SRS-99010 Spectralon ${ }^{\circledR}$ diffuse white standard provided by Labsphere (North Sutton, NH, USA) and acquired for $10 \mathrm{~ms}$. Spectra were not corrected nor normalized unless otherwise indicated.

The system was managed by the OceanView 1.6.7 software for Windows and data processed with OriginLab 8.0.

\section{Raman spectroscopy}

Micro-Raman spectroscopy spectra were acquired with a Bruker Senterra Raman spectrometer coupled with an LMPlanFL Olympus $50 \times$ long working distance microscope objective and a charge-coupled device (CCD) detector. A continuous wave diode laser, emitting light at $785 \mathrm{~nm}$, was used as the excitation source, and a 1200 rulings $/ \mathrm{mm}$ holographic grating provided a spectral resolution of $3-5 \mathrm{~cm}^{-1}$. All Raman spectra presented in this work were recorded with $1 \mathrm{~mW}$ output laser power at the sample. Acquisition time varied upon the color investigated. For the blue and green areas, the acquisition time was of $4 \mathrm{~min}$ (four successive $60 \mathrm{~s}$ accumulations), while it was set to $1 \mathrm{~min}$ (two successive $30 \mathrm{~s}$ accumulations) for the yellow particles. These parameters are well suited to avoid structural modifications to the Prussian blue while still allowing spectra with acceptable signal to noise ratio [17]. The blue colorants spectra were acquired in the $1515-2635 \mathrm{~cm}^{-1}$ range permitting the visualization of the characteristic bands of both indigo and Prussian blue while the yellow particles were acquired in the $60-1500 \mathrm{~cm}^{-1}$ range, suitable for most yellow inorganic pigments. Spectra were acquired using OPUS 7.0 Raman software and processed with OriginLab 8.0. Spectra were not corrected nor normalized unless otherwise indicated.

\section{Results and discussion}

The first problem in the investigation of the three impressions of Mishima Pass in Kai Province (Kōshū Mishima goe) was establishing the relative chronology of printing for the three sheets. The three prints present similar outlines and composition, indicating that they were most probably printed from the same set of woodblocks, as opposed to a later recut woodblock. They all represent three travelers embracing the enormous trunk from the site of the ancient cryptomeria tree they have just triumphantly reached. Mishima Pass is believed to be around the present Kagosaka Pass, ca. $60 \mathrm{~km}$ west of Yokohama. The prints present clear variations in color tones. Prints A and B are very similar: the coloring of Mount Fuji, the blue haze in the sky, and a similar gradation of the 
blue/green of the grass on the foreground. The coloring of print $\mathrm{C}$ appears quite different, with Mount Fuji and the grassy area in the foreground fully colored and a reddish haze in the sky. This emphasizes the singularity of print $\mathrm{C}$ compared to prints $\mathrm{A}$ and $\mathrm{B}$. The color variations observed may indicate either a similar time of production for print $A$ and $B$ and a later printing for $C$ or a later reedition of print $B$ following the print $A$ models, as it has been observed for other Hokusai's series [8]. Nonetheless, it is difficult to address this question solely based on colors. Line quality is the parameter most generally used to assess the relative time production of separate impressions of the same print. During the printing of a series of sheets from the same keyblock (the printing block carrying the outline design for the composition) the sharp wooden ridges of the block wear as a result of the printing pressure, and may eventually break. As a result, the sharpness of the printed lines can decrease, and breaks can appear in the outlines. When looking at the three prints studied here, we can observe great variations in the quality of cartouche and signature characters as well as the outlines. Lines in print A are fine and precise (Fig. 1b), most likely indicating an early stage printing, while lines in prints $B$ and $C$ are broader to the point that some cartouche characters are difficult to read (Fig. 1d, f). This most likely indicates a later stage in the printing process. While the cartouche can be used to determine the printing chronology of the prints, it may also lead to erroneous conclusions. In later impressions, the cartouche may have been carved again and substituted to the original one. The wear and breaks in the rest of the keyblock then appear more reliable. With the idea of creating a chronology to this particular set, we looked closely at the outlines from the slope of Mount Fuji and the clouds over its summit. Some wear was observed in prints B and $\mathrm{C}$ but is absent in print A (red arrows in Fig. 1), therefore confirming its earlier printing state. Furthermore, the wear in the clouds over Mount Fuji summit appears greater in print $C$ than in print $B$ (black arrows in Fig. 1). This would indicate that print $\mathrm{B}$ was realized prior to print $C$. The black outline of print $C$ is also characteristic of a reedition of Hokusai views expected to have been realized in the mid-1830s, along or following the creation of additional ten views for the "Thirty-Six Views of Mount Fuji" series. Therefore, print B is expected to have been realized in the first half the 1830s, before the black outlines reedition of the views.

In the case of print $\mathrm{D}$, the date of issue is given by a date seal. Actor prints were ephemeral, being linked to a specific production of the play described in the title, and were generally not reissued at later dates. While print D presents many more colors than the three Hokusai prints, only the green and yellow areas were of interest in this study. Nonetheless, all pigments and colorants identified in print D will be reported. All FORS and Raman analyses realized on all four prints yielded similar results with no significant variations within the blue/ green color palette. Only representative spectra are presented in Figs. 3, 4. FORS and Raman highlighted the typical palette expected for blue, green and yellow colorants in Japanese Edo-period prints [3, 18, 19]: (1) indigo, characterized by its broad absorption band in the $400-700 \mathrm{~nm}$ range (FORS) and a strong band at $1573 \mathrm{~cm}^{-1}$ (Raman); (2) Prussian blue, characterized by its significant absorption in the near infrared (NIR) range (FORS) and a strong band at $2155 \mathrm{~cm}^{-1}$ (Raman); and (3) arsenic sulfide suggested in FORS by the small inflection point observed around $470 \mathrm{~nm}$ and positively identified
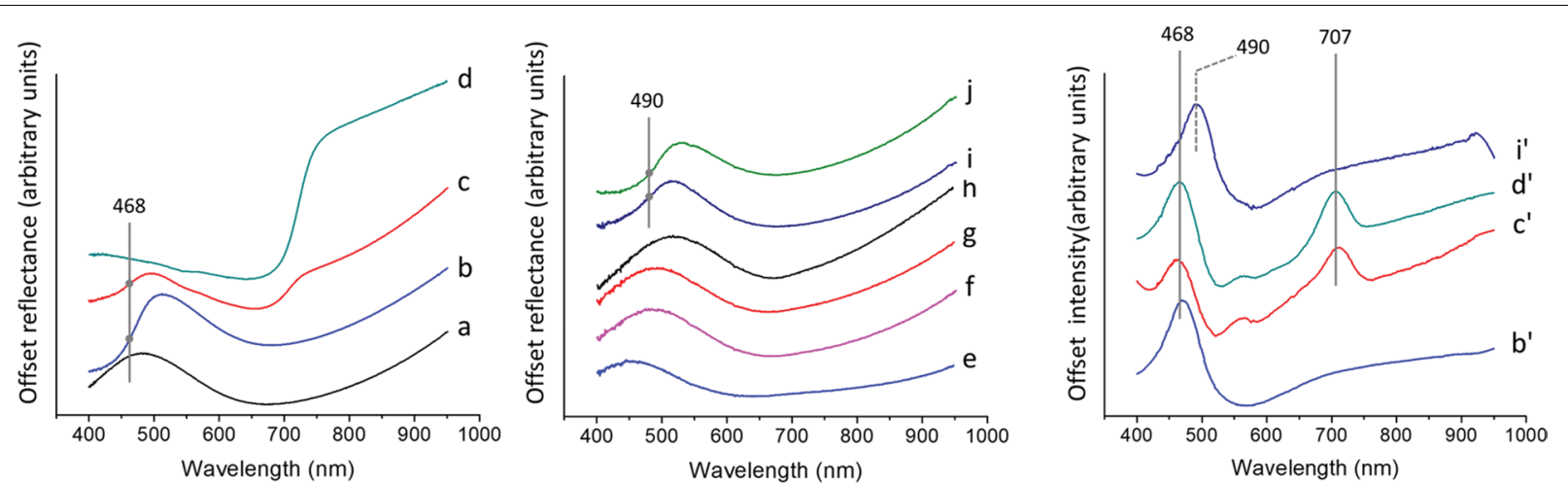

Fig. 3 FORS data obtained on the (a) blue, (b) green, (c) dark green and (d) outline areas of the three prints by Hokusai; and (e-h) various blues and $(\mathrm{i}, \mathrm{j})$ various greens of the print by Kunishada. The large absorption band in the NIR (700-950 nm) suggests Prussian blue, the inflection point at $468 \mathrm{~nm}$ in (b), (c), and $490 \mathrm{~nm}$ in (i) and (j) suggests the presence of arsenic sulfide and the large 400-700 $\mathrm{nm}$ absorption in band in (c) and (d) suggests indigo. Inflexion point at 468 and $490 \mathrm{~nm}$ (arsenic sulfide) and at $707 \mathrm{~nm}$ (indigo) are further highlighted by plots $\left(b^{\prime}\right),\left(c^{\prime}\right)\left(d^{\prime}\right)$ and $\left(i^{\prime}\right)$, first derivatives of respective (b), (c), (d) and (i) curves 

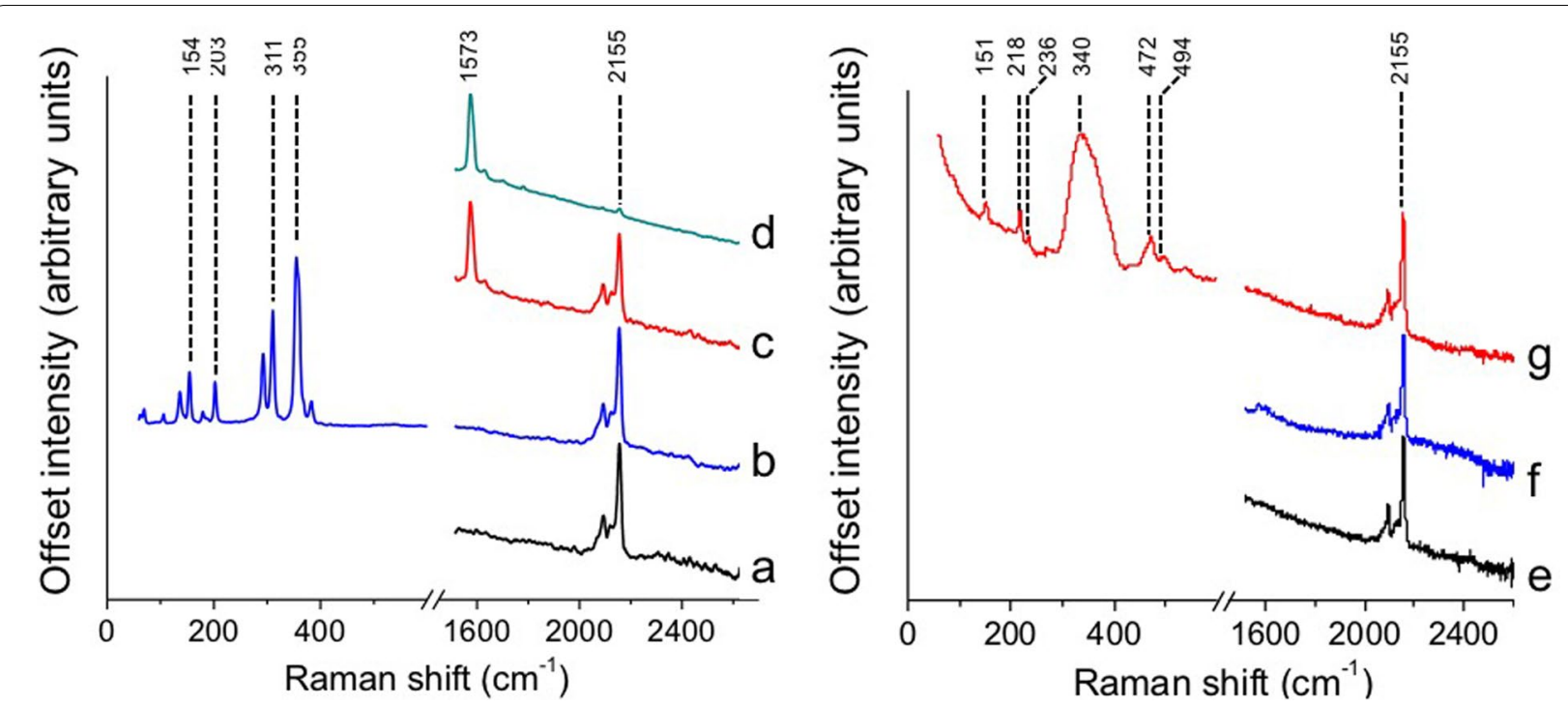

Fig. 4 Raman spectra of (a) the blue areas, (b) the green areas, (c) the dark blue areas and (d) the blue outline of the words in the cartouche in print A, B and C; and (e) dark blue, (f) the light blue, and (g) the green in print D. Unless orpiment was foreseen, only the $1550-2600 \mathrm{~cm}^{-1}$ region of the Raman spectra was measured as characteristic contributions for both indigo and Prussian blue are found in this region. In Raman spectroscopy, the contributions observed between 100 and $600 \mathrm{~cm}^{-1}$ correspond to natural arsenic sulfide in prints by Hokusai (A-C) and to artificial arsenic sulfide in the print by Kunisada (D); the one at 1573 indicates indigo and the pair of contributions between 2095 and $2155 \mathrm{~cm}^{-1}$ correspond to Prussian blue

as natural orpiment in Raman based on its characteristic bands $\left(106,136,154,179,203,293,311,355,384 \mathrm{~cm}^{-1}\right)$. Band assignments for natural orpiment and amorphous arsenic sulfides have been published previously and will therefore not be discussed here [20,21]. It is important to note that inflection points in FORS are not clear identifiers for yellow colorants-including orpiment-as the they can shift depending on the color of the support and change if the yellow is faded. This is clearly illustrated with spectra $\left(b^{\prime}\right),\left(c^{\prime}\right)$ and $\left(d^{\prime}\right)$, all form the Hokusai prints and presenting an inflection point at $468 \mathrm{~nm}$, while (i'), originating from a different print, present an inflection point at $490 \mathrm{~nm}$. Despite the difference in inflection points, all green mixtures in the prints are composed of Prussian blue and arsenic sulfide pigments. The difference can therefore be attributed to either a slight shift in inflection point between natural and artificial arsenic sulfide, an influence of the substrate or an effect of the fading of the pigments/colorants. Inflection points in the $400-500 \mathrm{~nm}$ region are however good indications that a yellow colorant/pigment is present and needs to be further investigated with other techniques such as XRF, Raman or SERS. Most hues found in the Hokusai prints (A, B and C) appear to be mixtures. Prussian blue was the only pigment identified alone in the bright blue areas of the sky, Mount Fuji, and the clothes (Figs. 3a, 4a). All blue areas in Kunisada's print (D) are printed with Prussian blue, most likely at various concentrations (Figs. 3e-h, 4e, f). In all four prints, Prussian blue was mixed with arsenic sulfide to yield green (Figs. 3b, c and i, j; 4b, g), while indigo was identified in prints by Hokusai along with Prussian blue in the darker shades of green and blue (Figs. 3c, 4c) and in the outlines (Fig. 4d). The outline for prints $\mathrm{C}$ and $\mathrm{D}$ was identified as being carbon-based (data not shown). FORS, XRF, Raman and SERS analyses on print $\mathrm{D}$ also identified iron oxide and safflower for the reds, turmeric for the yellow, iron oxide for the brown and an organic purple, which exact composition is currently being investigated.

Microscopic observations of the green from the tree trunk in prints A and B (Fig. 5) allows a clear visualization of the color difference between the two prints. The color variation could be due to a different concentration in both the blue and yellow pigments, as well as to small differences in hues of the two pigments used in the mixture. However, neither FORS nor Raman spectroscopy are suitable techniques to answer these hypotheses. The only significant difference that can be noticed is the presence of coarse dull orange particles in print B (Fig. 5b), while only smaller bright yellow particles are observed in prints A and C (Fig. 5a).

Raman analysis of the dull orange particles of print $B$ and of all yellow particles from print $D$ reveal an intense and broad band at $340 \mathrm{~cm}^{-1}$, smaller bands at 233, 271, 475 (print D) and $495 \mathrm{~cm}^{-1}$ and an increased background in the $100-250 \mathrm{~cm}^{-1}$ area (Fig. 6a, e, f). This 

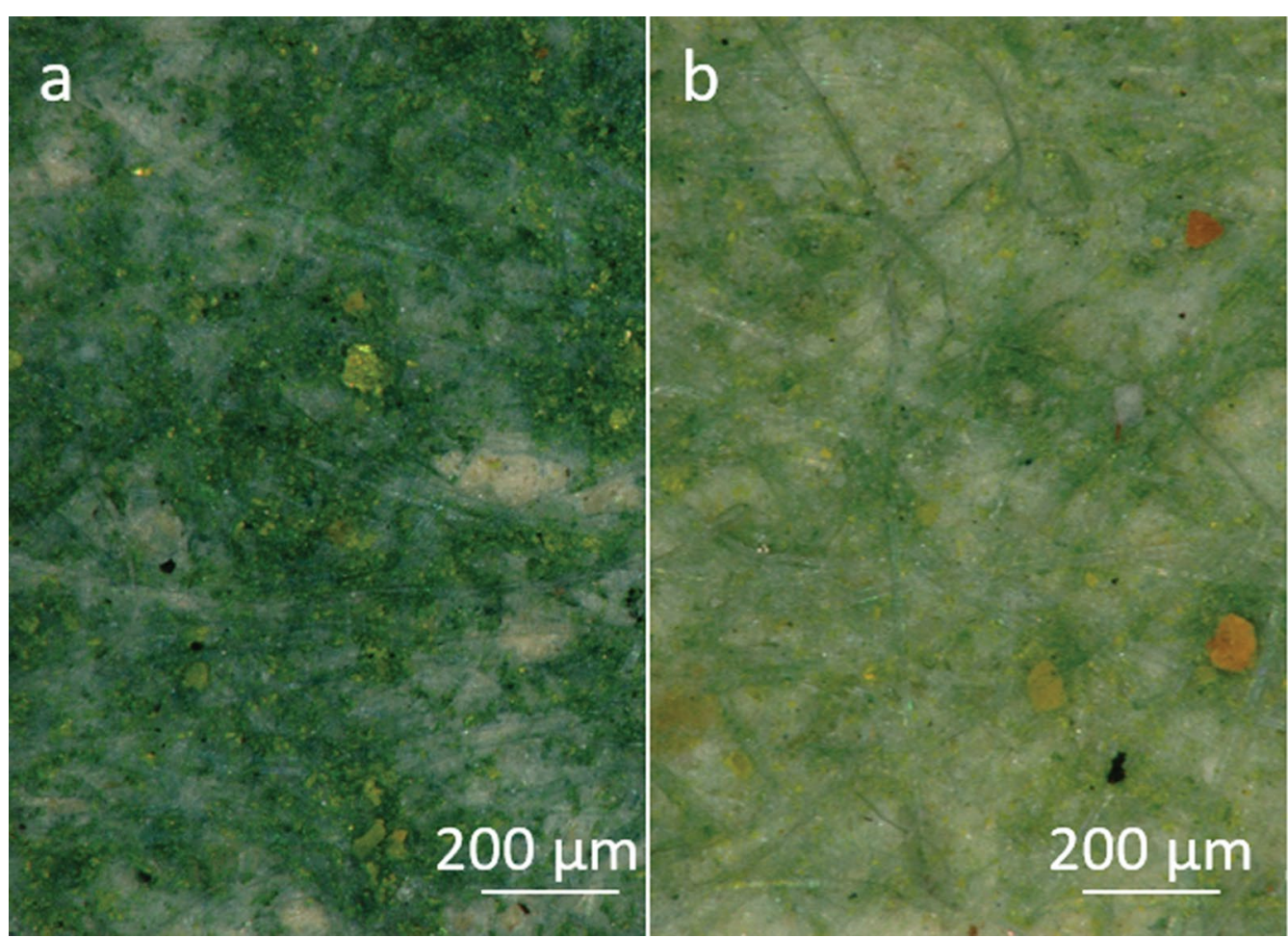

Fig. 5 Digital images $(\times 200)$ under visible light of the green areas of the tree in (a) print A and $(\mathbf{b})$ print B. Print B presents both bright yellow and coarse dull orange arsenic sulfide particles (red circles) while print A (and C) only present bright yellow crystal-looking arsenic sulfide particles
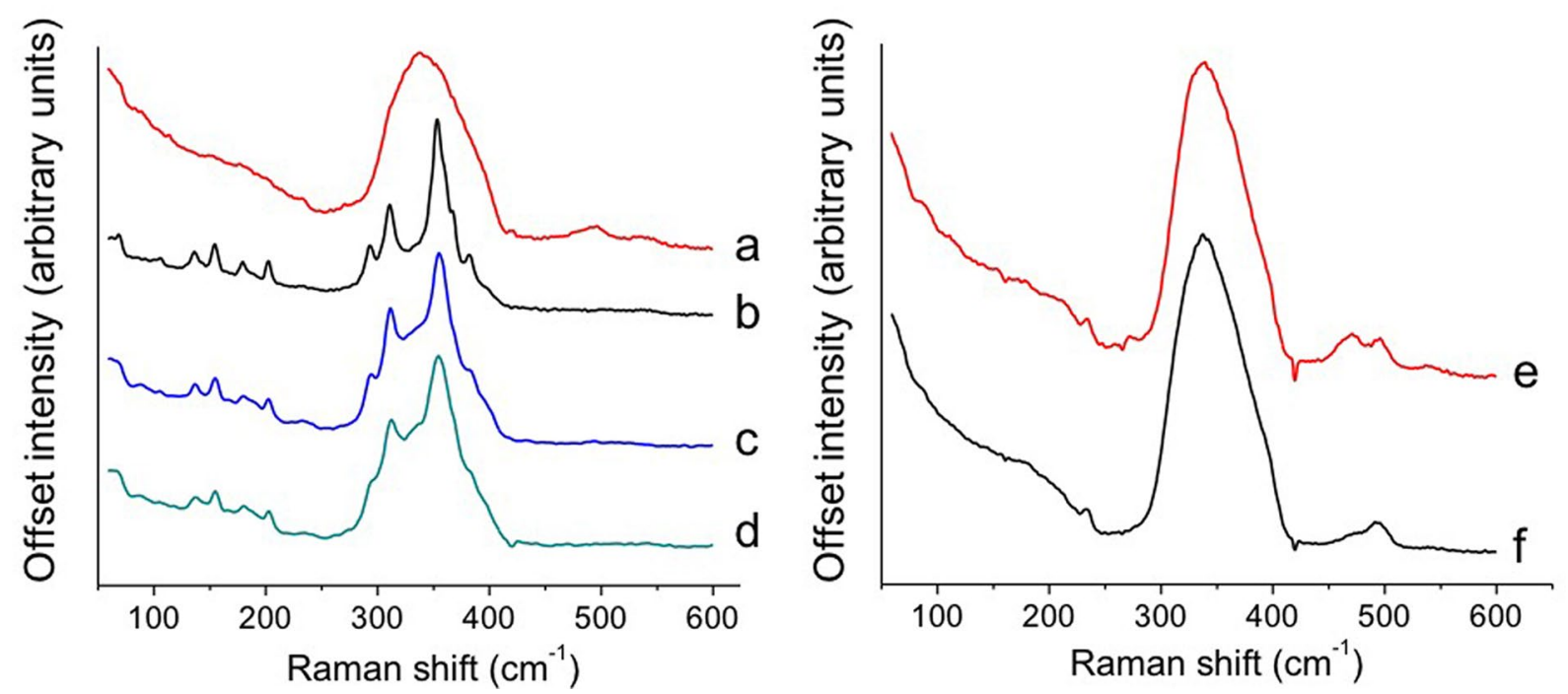

Fig. 6 Selected normalized Raman spectra of (a) and (b) orange particles in print B, (c) and (d) orange particles in two other prints from Hokusai Thirty-six Views of Mount Fuji series (respectively JP22 and JP1295) and (e) and (f) from yellow particles in print D. (a), (e) and (f) are characteristic for fully amorphous arsenic sulfide particles while (b), (c) and (d) present characteristic bands for both crystalline and amorphous forms of the pigment

profile and particular contributions are characteristic for the various bending and stretching bonds found in amorphous arsenic sulfide pigments, as reported in previous arsenic sulfide characterization studies [14, 22, 23]. While not previously reported as a characteristic for amorphous arsenic sulfide pigments, the increase in 
the $100-250 \mathrm{~cm}^{-1}$ region has consistently been noted in non-background corrected spectra in identification studies of amorphous arsenic sulfide pigments $[8,10,14,20$, $22]$. This can therefore be used along the main Raman contributions as a secondary indication that amorphous arsenic sulfide pigment is present.

The main band centered around $340 \mathrm{~cm}^{-1}$ is a clear indicator of the amorphous nature of the arsenic sulfide pigment $[14,22,24]$. All other smaller contributions provide information on the initial materials used for the synthesis and the synthesis process by itself. While the bands at 271 and $495 \mathrm{~cm}^{-1}$ indicate the use of sulfur, the bands at 233 and $475 \mathrm{~cm}^{-1}$ are characteristic for realgar-like nano phases, themselves indicative of a dry-process synthetic method [14, 22, 25].

Other dull orange particles in print $B$ present the characteristic bands for both natural and amorphous arsenic sulfide pigments: all bands for the natural pigment reported previously, a broadening of the contribution between 300 and $400 \mathrm{~cm}^{-1}$ and a smaller-but significant-increase of the baseline in the $100-250 \mathrm{~cm}^{-1}$ region (Fig. 6b). Similar particles were also identified in other prints from the "Thirty-Six Views of Mount Fuji" (19 out of 52 prints analyzed with Raman spectroscopy to date) that present either yellow and/or green areas. Two examples of the 19 prints presenting the characteristics consistent with a partially recrystallized (or sublimated) orpiment ore are given in Fig. 6c, d. Arsenic sulfide particles analyzed in print $\mathrm{D}$ present all characteristics of the amorphous arsenic sulfide pigment: broad band centered around $340 \mathrm{~cm}^{-1}$, realgar-like nano-phases at 233 and $475 \mathrm{~cm}^{-1}$, sulfur remnants at 271 and $495 \mathrm{~cm}^{-1}$ as well as the increased baseline between 100 and $250 \mathrm{~cm}^{-1}$ (Fig. 6e, f). No traces of natural orpiment were identified in the latter particles.

Raman spectroscopy is the only technique capable of differentiating non-invasively between natural and artificial arsenic sulfide. As such, it gives access to crucial information regarding the evolution of the production of artificial arsenic sulfide pigment. While amorphous arsenic sulfide was previously identified in Japanese woodblock prints, both studies reported perfectly amorphous particles similar to Fig. 6a, e, f $[8,10]$. No study focusing on Japanese woodblock prints - or Japanese art in general-reported partially sublimed amorphous arsenic sulfide as presented in Fig. $6 \mathrm{~b}-\mathrm{d}$. As such, the results reported here represent major findings regarding the production and use of the amorphous arsenic sulfide production in Edo-period Japan.

In a previous article on the study of Hokusai's "A Tour of Waterfalls in Various Provinces" series, the authors hypothesized, based on literary sources and on the lack of arsenic oxide in the prints that the amorphous arsenic sulfide identified was obtained by sublimation of natural orpiment imported from China with or without the addition of sulfur [8]. However, no Raman bands indicative of natural orpiment or sulfur could be identified in the spectra and therefore indicate a synthesis from the natural pigment. As both the amorphous and natural pigments contributions are found in single analyzed particles, our results however support the hypothesis of a synthesis using natural orpiment as starting material. Furthermore, the presence of all three forms of the pigment in print $\mathrm{B}$-fully crystalline, semi amorphous and fully amorphous-suggests a low grade pigment compared to the all fully amorphous pigment particles found in Hokusai Waterfall series. The presence of low grade arsenic sulfide pigments on the Japanese market is also supported by texts by Gray [26] and Geert [27], describing a second quality dull-orange pigment masses that can be bought cheaply. Finding it in a Japanese print is also in line with the idea of Japanese woodblock prints being a mass-produced, "cheap" art form, which production costs must be kept as low as possible. The weak contributions for free sulfur at 271 and $495 \mathrm{~cm}^{-1}$ (Fig. 6a, e, f) indicate that sulfur was added to the natural pigment before heat treatment. The origin of the starting material is difficult to assess with certainty and could therefore come from China or be mined in Japan as both ores would be very similar. Scientific analysis would need to be correlated with local historical paint technology and scientific literature to gain further understanding of the production process and origin of the materials. Japanese artists or technological literature is rather scarce and only few report pigment sources and/or preparation procedures. Toyokichi Takamatsu's 1878 treatise "On Japanese pigments" is one of the most comprehensive and enlightening sources of information regarding the pigments and colorants used in Japanese artifacts in the nineteenth century [28]. In this treatise, Takamatsu, a Japanese chemist specialized in coloring materials, describes the happenstance discovery that led to the production of amorphous arsenic sulfide in the northern province of Iwashiro (an old province in the area of nowadays Fukushima Prefecture) in 1846. He reports an experiment in which an arsenical stone (yoseki) and sulfur where mixed and burned leading to the formation of a yellow substance identified as sekiwo. The preparation process is analogous to the eighteenth-century dry process European preparation, in which arsenic oxide and sulfur were mixed and heated [14]. Terminology around arsenic ores is rather complex, and orpiment and arsenic-containing minerals have borne various names. Arsenic oxide, for example, appears to be described by two very similar names: yo$s e k i$ and $h i$-seki, $h i$ being the standard modern term for "arsenic", $y \bar{o}$ an older Chinese term and seki simply means 
"stone" [29-31]. All literature sources seem to agree that sekiwo is the amorphous product obtained following heat processing of natural ores or arsenic oxide and sulfur mixtures. Natural orpiment is often referred as shiwo or kin-yeki in Japanese literature [27]. Therefore, yoseki, used by Takamatsu, most likely does not refer to the natural ore. In China, this word normally referred to arsenopyrite $(\mathrm{FeAsS})$ or the related mineral loellingite $\left(\mathrm{FeAs}_{2}\right)$; in Japan, however, this word was often understood to refer to arsenolite $\left(\mathrm{As}_{2} \mathrm{O}_{3}\right)$ [32]. Therefore, this description from 1846 would not correspond to the pigment identified in the Hokusai prints studied here (A, B, and C) but would be in line with the arsenic sulfide pigment identified in the print by Kunisada (D). This also suggests that the technology used in 1846 yields fully amorphous arsenic sulfide pigment that is being introduced in works of art quite rapidly in the late Edo-period and thoroughly by the Meiji-period. The Kunisada 1852 print marks to date, the earliest use of fully amorphous arsenic sulfide in Japanese woodblock prints.

The knowledge and technology required for the production of arsenic sulfide pigments from natural orpiment were commonplace in Europe-and most likely China [14, 33-36]. We can imagine that the same processes may have been available in Japan well before the 1840s. This is suggested by an application for submission of refined orpiment to the first Japanese national domestic exposition of 1877 [31]. In this text, the author states that a natural orpiment mine was discovered in Tagokura-mura in May 1874. The extraction and refining of the natural ore started as early as July of the same year. The refining was made by finely breaking up the orpiment, removing the sandy rocks (impurities), placing it into an earthen pot and heating it along with sulfur until melting point is reached. The refinement process described in the text implies that the whole method was fully developed and therefore set much earlier than the discovery of the orpiment mine in early 1874 . It also implies that the amorphous arsenic sulfide produced in Japan in the second half of the nineteenth century was using natural pigment as the main source of arsenic. An early production of amorphous arsenic sulfide from natural orpiment in Japan is further supported by Gray's 1831 "Supplement to the Pharmacopoeia, and Treatise on Pharmacology in general" [26]. In this literary source, Gray describes King's yellow-an artificial arsenic sulfide pigment-as obtained through sublimation of natural orpiment and originating "from China, Japan, and the Burman empire". Similar Raman spectra as those obtained on the 1830s Hokusai prints were reported in Burmese lacquered objects dated from 1831 [37], emphasizing the local production of amorphous arsenic sulfide from natural orpiment and its use in art objects.
Therefore, from these various literary sources, it appears very probable that artificial arsenic sulfide pigments were being produced in Japan as early as 1830 , most likely from sublimation of natural orpiment mined in Japan. Later on, the production process presumably shifted toward the use of arsenic oxide as main source of arsenic, and may correspond to what Zaleski et al. [8] and Luo et al. [10] found in their late-Edo and Meiji-period Japanese prints. Even though the literature sources support a local mining and transformation of arsenic sulfide into the amorphous pigment, the importation of arsenicbased pigment from China is not questioned as often described [27, 28]. More research on elemental and/or spectroscopic markers of arsenic sulfide materials production from both countries would be required to be able to differentiate them and trace the origin of the pigment found in the artworks.

Finally, the semi-amorphous arsenic sulfide particles are found throughout the set of Hokusai prints from the Met collection as well as in other Asian objects from the 1830 s while fully amorphous are found exclusively in prints post 1850 . This could be used as an indicator for print dating along with the line quality and other pigments and colorants such as Prussian blue, ultramarine blue or synthetic organic colorants.

\section{Conclusion}

Non-invasive and microanalytical techniques were applied to the study of the color palette used in Japanese woodblock prints belonging to the "Thirty-Six Views of Mount Fuji" collection from the Metropolitan Museum of Art and from a print by Kunisada dated 1852 in a private collection. All techniques highlighted a limited conventional palette for blues and greens composed of indigo, Prussian blue and arsenic sulfide yellow. Raman spectroscopy, the only technique to date allowing the differentiation between natural and artificial arsenic sulfide pigments, positively identified fully and semi sublimated artificial arsenic sulfide pigment particles along with crystalline bright yellow natural orpiment in prints by Hokusai (1830s) and fully amorphous arsenic sulfide in the print by Kunisada (1852). While only expected in lateEdo/early-Meiji prints, the state of the keyblocks tend to indicate that the Hokusai impression in which the artificial pigment has been identified was created before the mid-1830s black-line reedition of the view, placing therefore all prints in the Japanese Edo-period. Supported by Japanese artists and Japan-based industrial literature, this identification corresponds to the first occurrence of synthetic arsenic sulfide pigment in Japanese art and proves that synthetic arsenic sulfide pigments were produced in Japan in the first half of the nineteenth century. This study also highlights the evolution of the production 
processes of amorphous arsenic sulfide pigments in Japan, starting with the sublimation of natural pigments in the 1830s and moving to a melt/quench process based on arsenic oxide and sulfur in the 1850s. More work is required to further narrow down the time window, but the data presented can already be used to date prints, with semi-amorphous arsenic sulfide pigment indicative of prints produced before 1850 and fully amorphous arsenic sulfide pigments characteristic for prints created after 1852 .

\section{Abbreviation}

FORS: fiber optic reflectance spectroscopy.

\section{Acknowledgements}

This research is made possible by an Andrew W. Mellon Foundation postdoctoral fellowship. We gratefully acknowledge John T. Carpenter, Mary Griggs Burke Curator of Japanese Art at The Metropolitan Museum of Art for his support and advice. The authors also gratefully acknowledge Henry D. Smith II for providing the Kunisada print and valuable historical facts as well as Janie Woo for her help with FORS data acquisition.

\section{Authors' contributions}

MV was responsible for the conception and design of the work, acquisition and interpretation of FORS and Raman data and drafting the paper. ML contributed to the interpretation of data and substantively revised the paper. Both authors read and approved the final manuscript.

\section{Funding}

Non applicable.

\section{Availability of data and materials}

All data is available upon request.

\section{Competing interests}

The authors declare that they have no competing interests.

Received: 22 July 2019 Accepted: 16 September 2019

Published online: 27 September 2019

\section{References}

1. Vandeperre N, Herwig H. Ukiyoe: les plus belles estampes japonaises. Gent: Snoeck Publishers; 2016.

2. Tinios E, Utagawa K. Mirror of the stage: the actor prints of Kunisada. Leeds: University Gallery Leeds; 1996.

3. Korenberg C, Pereira Pardo L, McElhinney PJ, Dyer J. Developing a systematic approach to determine the sequence of impressions of Japanese woodblock prints: the case of Hokusai's'Red Fuji'. Herit Sci. 2019;7:1-11. https://doi.org/10.1186/s40494-019-0250-5.

4. Eastaugh N. Scientific dating of paintings. Infocus Mag. 2006;1:31-9.

5. Burgio L, Clark RJH, Sheldon L, Smith GD. Pigment identification by spectroscopic means: evidence consistent with the attribution of the painting young woman seated at a virginal to Vermeer. Anal Chem. 2005;77:12617. https://doi.org/10.1021/ac048481i.

6. Khandekar N, Mancusi-Ungaro C, Cooper H, Rosenberger C, Eremin K, Smith $\mathrm{K}$, et al. A technical analysis of three paintings attributed to Jackson Pollock. Stud Conserv. 2010;55:204-15. https://doi.org/10.1179/ sic.2010.55.3.204.

7. Chaplin T, Jurado-López A, Clark RJH, Beech DR. Identification by Raman microscopy of pigments on early postage stamps: distinction between original 1847 and 1858-1862, forged and reproduction postage stamps of Mauritius. J Raman Spectrosc. 2004;35:600-4. https://doi.org/10.1002/ jrs. 1208.
8. Zaleski S, Takahashi Y, Leona M. Natural and synthetic arsenic sulfide pigments in Japanese woodblock prints of the late Edo period. Herit Sci. 2018. https://doi.org/10.1186/s40494-018-0195-0.

9. Cesaratto A, Luo Y-B, Smith HD, Leona M. A timeline for the introduction of synthetic dyestuffs in Japan during the late Edo and Meiji periods. Herit Sci. 2018. https://doi.org/10.1186/s40494-018-0187-0.

10. Luo Y, Basso E, Smith HD, Leona M. Synthetic arsenic sulfides in Japanese prints of the Meiji period. Herit Sci. 2016. https://doi.org/10.1186/s4049 4-016-0087-0.

11. Derrick M, Newman R, Wright J. Characterization of yellow and red natural organic colorants on Japanese woodblock prints by EEM fluorescence spectroscopy. J Am Inst Conserv. 2017. https://doi.org/10.1080/01971 360.2016.1275438.

12. Derrick M, Wright J, Newman R. Plant dye identification in Japanese woodblock prints. Arnoldia. 2017;74:12-28.

13. Smith HD. Hokusai and the blue revolution in Edo prints. In: Carpenter JT, editor. Hokusai his age Ukiyo-E Paint. Printmak. Book Illus. Late Edo Jpn. Amsterdam: Hotei; 2005. p. 234-69.

14. Vermeulen M, Palka K, Vlcek M, Sanyova J. Study of dry- and wet-process amorphous arsenic sulfides: synthesis, Raman reference spectra and identification in historical art materials. J Raman Spectrosc. 2018;50:396-406. https://doi.org/10.1002/jrs.5534.

15. Mounier A, Le Bourdon G, Aupetit C, Lazare S, Biron C, Pérez-Arantegui J, et al. Red and blue colours on 18th-19th century Japanese woodblock prints: in situ analyses by spectrofluorimetry and complementary noninvasive spectroscopic methods. Microchem J. 2018;140:129-41. https:// doi.org/10.1016/j.microc.2018.04.023.

16. Biron C, Le Bourdon G, Pérez-Arantegui J, Servant L, Chapoulie R, Daniel F. Probing some organic Ukiyo-e Japanese pigments and mixtures using non-invasive and mobile infrared spectroscopies. Anal Bioanal Chem. 2018:410:7043-54. https://doi.org/10.1007/s00216-018-1305-2.

17. Moretti G, Gervais C. Raman spectroscopy of the photosensitive pigment Prussian blue. J Raman Spectrosc. 2018;49:1198-204. https://doi. org/10.1002/jrs.5366.

18. Winter J. East Asian paintings: materials, structures and deterioration mechanisms. London: Archetype Publications, Freer Gallery of Art and Arthur M. Sackler Gallery, Smithsonian Institution; 2008.

19. FitzHugh EW. A database of pigments on Japanese Ukiyo-e paintings in the Freer Gallery of Art. Pigments Later Jpn. Paint. Stud. Using Sci. Methods, vol. 1. Washington, D.C.: Freer Gallery of Art, Smithsonian Institution; 2003. p. 1-56.

20. Vermeulen M, Nuyts G, Sanyova J, Vila A, Buti D, Suuronen J-P, et al. Visualization of $\mathrm{As}(\mathrm{III})$ and $\mathrm{As}(\mathrm{V})$ distributions in degraded paint microsamples from Baroque- and Rococo-era paintings. J Anal At Spectrom. 2016;31:1913-21. https://doi.org/10.1039/c6ja00134c.

21. Vermeulen M, Saverwyns S, Coudray A, Janssens K, Sanyova J. Identification by Raman spectroscopy of pararealgar as a starting material in the synthesis of amorphous arsenic sulfide pigments. Dyes Pigments. 2018;149:290-7. https://doi.org/10.1016/j.dyepig.2017.10.009.

22. Vermeulen M, Sanyova J, Janssens K. Identification of artificial orpiment in the interior decorations of the Japanese tower in Laeken, Brussels, Belgium. Herit Sci. 2015. https://doi.org/10.1186/s40494-015-0040-7.

23. van Loon A, Noble P, Krekeler A, Van der Snickt G, Janssens K, Abe Y, et al. Artificial orpiment, a new pigment in Rembrandt's palette. Herit Sci. 2017. https://doi.org/10.1186/s40494-017-0138-1.

24. Grundmann G, Ivleva N, Richter M, Stege $H$, Haisch C. The rediscovery of sublimed arsenic sulphide pigments in painting and polychromy: applications of Raman microspectroscopy. In: Spring M, Howard H, Christensen C, Lomax SQ, Palmer M, Wilcox S, et al., editors. Stud. Old Master Paint. Technol. Pract. Natl. Gallery Tech. Bull. 30th Anniv. Conf. Postprints, London: Archetype Publications : in association with the National Gallery; 2011. p. 269-76.

25. Georgiev DG, Boolchand P, Jackson KA. Intrinsic nanoscale phase separation of bulk As2S3 glass. Philos Mag. 2003;83:2941-53. https://doi. org/10.1080/1478643031000151196.

26. Gray SF. A supplement to the pharmacopoeia and treatise on pharmacology in general. London: T. \& G. Underwood; 1831.

27. Geerts AJC. Useful minerals and metallurgy of the Japanese. Transactions of the Asiatic Society of Japan. vol. 3:2. 1876.

28. Takamatsu T. On Japanese pigments. Tokyo: Department of Science in Tokio Daigaku; 1878. 
29. FitzHugh EW. Orpiment and realgar. In: FitzHugh EW, editor. Artists Pigments Handb. Their Hist. Charact., vol. 3. Washington: National Gallery of Art; 1997. p. 47-79.

30. Vermeulen M. Natural and amorphous arsenic sulfide pigments: charac terization, degradation and influence of the binding medium (Doctoral dissertation). University of Antwerp; 2017.

31. Smith HD. Email personal communication 2018.

32. Trambaiolo D. Syphilis and seiseinyū: manufacturing a mercurial drug in early modern Japan. Recipes Proj - Food Magic Art Sci Med. 2015. https:// recipes.hypotheses.org/5086. Accessed 4 Mar 2019.

33. Merrifield MP. Original treatises dating from the XIIth to XVIIIth centuries on the arts of painting, in oil, miniature, mosaic and on glass. vol. 1. Originally published John Murray, London, 1849. New York: Dover Publications; 1999.

34. Merrifield MP. Medieval and renaissance treatises on the arts of painting: original texts with English translations. North Chelmsford: Courier Corporation; 2012.
35. Wallert A. Orpiment and realgar, some pigment characteristics. Maltechnik Restauro. 1984;90:45-58.

36. Schafer Edward. Orpiment and realgar in Chinese technology and tradition. J Am Orient Soc. 1955;75:73-89. https://doi.org/10.2307/595009.

37. Tamburini D, Kotonski V, Lluveras-Tenorio A, Colombini MP, Green A. The evolution of the materials used in the yun technique for the decoration of Burmese objects: lacquer, binding media and pigments. Herit Sci. 2019. https://doi.org/10.1186/s40494-019-0272-z.

\section{Publisher's Note}

Springer Nature remains neutral with regard to jurisdictional claims in published maps and institutional affiliations.

\section{Submit your manuscript to a SpringerOpen ${ }^{\circ}$ journal and benefit from:}

- Convenient online submission

- Rigorous peer review

- Open access: articles freely available online

- High visibility within the field

- Retaining the copyright to your article

Submit your next manuscript at $\boldsymbol{\nabla}$ springeropen.com 